\title{
Best proximity point theorems for generalized $\alpha$ - $\beta$-proximal quasi-contractive mappings
}

Mohamed ladh Ayari*

\section{"Correspondence:}

iadh_ayari@yahoo.com

Department of Mathematics and

Computer Science, Institut National

Des Sciences Appliquée et de

Technologie de Tunis, Carthage

University, Centre Urbain Nord BP

676, Tunis, 1080, Tunisia

\begin{abstract}
Herein, we search for some best proximity point results for a novel class of non-self-mappings $T: A \longrightarrow B$ called generalized proximal $\alpha$ - $\beta$-quasi-contractive. We illustrate our work by an example. Our results generalize and extend many recent results appearing in the literature. Several consequences are derived. As applications, we explore the existence of best proximity points for a metric space endowed with symmetric binary relation.
\end{abstract}

MSC: $47 \mathrm{H} 10 ; 54 \mathrm{H} 25$

Keywords: best proximity points; $\alpha$ - $\beta$-proximal quasi-contractive mappings on metric spaces

\section{Introduction}

Consider $A$ and $B$ two nonempty subsets of a metric space $(X, d)$. Let $T: A \longrightarrow B$ be a non-self-mapping. The best proximity points of $T$ are the points $x \in A$ satisfying $d(x, T x)=$ $d(A, B)$. Numerous works on best proximity point theory were studied by giving sufficient conditions assuring the existence and the uniqueness of such points. These theorems are a normal generalization of the contraction principle to the case of self-mappings. Several known results were derived. For additional information, see [1-7] and [8].

Recently, Samet et al. [9] introduced a novel class of contractive mappings called $\alpha-\psi$ contractive type mappings. They provided some interesting results to obtain the existence of fixed points for self-mappings. After that, Jleli et al. in [9] studied the existence and the uniqueness of best proximity points of non-self-mappings.

The main objective of this paper is to generalize the results of Jleli et al. [9] by introducing the proximal $\alpha$ - $\beta$-quasi-contractive mappings on metric spaces involving $\beta$-comparison functions.

In fact, we have derived some theorems on best proximity points for a specific class of proximal generalized $\alpha$ - $\beta$-quasi-contractive mappings. The presented results generalize the theorem of Jleli et al. [9] and many results existing in the literature. Moreover, we have shown that from our main theorems we are able to deduce various theorems of best proximity points for the case of metric spaces endowed with symmetric binary relations. Also, we have deduced some fixed point theorems already existing in the literature.

(c) The Author(s) 2017. This article is distributed under the terms of the Creative Commons Attribution 4.0 International License (http://creativecommons.org/licenses/by/4.0/), which permits unrestricted use, distribution, and reproduction in any medium, provided you give appropriate credit to the original author(s) and the source, provide a link to the Creative Commons license, and indicate if changes were made. 
The paper is divided into five sections. Section 2 is dedicated to the notation adopted to provide definitions and evoking a compilation of pertinent results. Best proximity point theorems with their proofs are stated in Section 3, and we justify our results by a suitable example. Several consequences are obtained in Section 4. Finally, the existence of best proximity points and fixed point results are given in Section 5 .

\section{Preliminaries and definitions}

Let $(A, B)$ be a pair of nonempty subsets of a metric space $(X, d)$. We adopt the following notations:

$$
\begin{aligned}
& d(A, B):=\inf \{d(a, b): a \in A, b \in B\} ; \\
& A_{0}:=\{a \in A: \text { there exists } b \in B \text { such that } d(a, b)=d(A, B)\} ; \\
& B_{0}:=\{b \in B: \text { there exists } a \in A \text { such that } d(a, b)=d(A, B)\} .
\end{aligned}
$$

Definition 2.1 ([10]) Let $T: A \longrightarrow B$ be a mapping. An element $x^{*}$ is said to be a best proximity point of $T$ if $d\left(x^{*}, T x^{*}\right)=d(A, B)$.

Definition $2.2([11])$ Let $\beta \in(0,+\infty)$. A $\beta$-comparison function is a map $\varphi:[0,+\infty) \rightarrow$ $[0,+\infty)$ fulfilling the following properties:

(1) $\varphi$ is nondecreasing;

(2) $\lim _{n \rightarrow \infty} \varphi_{\beta}^{n}(t)=0$ for all $t>0$, where $\varphi_{\beta}^{n}$ denotes the $n$th iterate of $\varphi_{\beta}$ and $\varphi_{\beta}(t)=\varphi(\beta t)$

(3) there exists $s \in(0,+\infty)$ such that $\sum_{n=1}^{\infty} \varphi_{\beta}^{n}(s)<\infty$.

The set of all $\beta$-comparison functions $\varphi$ satisfying (1)-(3) will be denoted by $\Phi_{\beta}$.

Remark 2.3 Let $\alpha, \beta \in(0,+\infty)$. If $\alpha<\beta$, then $\Phi_{\beta} \subset \Phi_{\alpha}$.

A useful lemma concerning the comparison functions $\Phi$ was performed in [11].

Lemma 2.4 ([11]) Let $\beta \in(0,+\infty)$ and $\varphi \in \Phi_{\beta}$. Then

(1) $\varphi_{\beta}$ is nondecreasing;

(2) $\varphi_{\beta}(t)<t$ for all $t>0$;

(3) $\sum_{n=1}^{\infty} \varphi_{\beta}^{n}(t)<\infty$ for all $t>0$.

Definition 2.5 ([7]) Let $(A, B)$ be a pair of nonempty subsets of a metric space $(X, d)$ such that $A_{0}$ is nonempty. Then the pair $(A, B)$ is said to have the P-property iff $d\left(x_{1}, y_{1}\right)=$ $d\left(x_{2}, y_{2}\right)=d(A, B) \Longrightarrow d\left(x_{1}, x_{2}\right)=d\left(y_{1}, y_{2}\right)$, where $x_{1}, x_{2} \in A$ and $y_{1}, y_{2} \in B$.

Definition 2.6 ([9]) Let $T: A \longrightarrow B$ and $\alpha: A \times A \longrightarrow[0,+\infty)$. We say that $T$ is $\alpha$ proximal admissible if $\alpha\left(x_{1}, x_{2}\right) \geq 1$ and $d\left(u_{1}, T x_{1}\right)=d\left(u_{2}, T x_{2}\right)=d(A, B) \Longrightarrow \alpha\left(u_{1}, u_{2}\right) \geq 1$ for all $x_{1}, x_{2}, u_{1}, u_{2} \in A$.

Definition 2.7 ([9]) A non-self-mapping $T: A \longrightarrow B$ is said to be a generalized $\alpha$ - $\psi$ proximal contraction, where $\alpha: A \times A \longrightarrow[0,+\infty)$ and $\psi$ is a (c)-comparison function if

$$
\alpha(x, y) d(T x, T y) \leq \psi(M(x, y)), \quad \forall x, y \in A,
$$


where

$$
\begin{aligned}
M(x, y)= & \max \left\{d(x, y), \frac{1}{2}[d(x, T x)+d(y, T y)]-d(A, B),\right. \\
& \left.\frac{1}{2}[d(y, T x)+d(x, T y)]-d(A, B)\right\} .
\end{aligned}
$$

Definition 2.8 ([9]) A non-self-mapping $T: A \longrightarrow B$ is said to be $(\alpha, d)$ regular, where $\alpha: A \times A \longrightarrow[0,+, \infty)$, if for all $(x, y)$ such that $0 \leq \alpha(x, y)<1$, there exists $u_{0} \in A_{0}$ such that

$$
\alpha\left(x, u_{0}\right) \geq 1 \text { and } \alpha\left(y, u_{0}\right) \geq 1
$$

\section{Main results and theorems}

First, we introduce the following concept.

Definition 3.1 Let $(X, d)$ be a metric space and $(A, B)$ be a pair of nonempty subsets of $X$. Let $\beta \in(0,+\infty)$. A non-self mapping $T: A \rightarrow B$ is said to be a generalized $\alpha$ - $\beta$-proximal quasi-contractive, where $\alpha: A \times A \longrightarrow[0,+, \infty)$ iff there exist $\varphi \in \Phi_{\beta}$ and positive numbers $\alpha_{0}, \ldots, \alpha_{4}$ such that

$$
\alpha(x, y) d(T x, T y) \leq \varphi\left(M_{T}(x, y)\right), \quad \forall x, y \in A,
$$

where

$$
\begin{aligned}
M_{T}(x, y)= & \max \left\{\alpha_{0} d(x, y), \alpha_{1}(d(x, T x)-d(A, B)),\right. \\
& \alpha_{2}(d(y, T y)-d(A, B)), \alpha_{3}(d(y, T x)-d(A, B)), \\
& \left.\alpha_{4}(d(x, T y)-d(A, B))\right\} .
\end{aligned}
$$

We propose the following best proximity point theorems.

Theorem 3.2 Let $(A, B)$ be a pair of nonempty closed subsets of a complete metric space $(X, d)$ such that $A_{0}$ is nonempty. Let $\alpha: A \times A \longrightarrow[0,+, \infty)$ and $\varphi \in \Phi_{\beta}$. Consider a nonself-mapping $T: A \longrightarrow B$ satisfying the following assertions:

(1) $T\left(A_{0}\right) \subset B_{0}$ and the pair $(A, B)$ satisfies the P-property;

(2) $T$ is $\alpha$-proximal admissible;

(3) there exist elements $x_{0}, x_{1} \in A$ such that $d\left(x_{1}, T x_{0}\right)=d(A, B)$ and $\alpha\left(x_{0}, x_{1}\right) \geq 1$;

(4) if $\left\{x_{n}\right\}$ a sequence in $A$ such that $\alpha\left(x_{n}, x_{n+1}\right) \geq 1$ and $\lim _{n \rightarrow+\infty} x_{n}=x_{*} \in A$, then there exists a subsequence $\left\{x_{n(k)}\right\}$ of $\left\{x_{n}\right\}$ such that $\alpha\left(x_{n(k)}, x_{*}\right) \geq 1$ for all $k$;

(5) there exists $\beta \geq \max _{0 \leq k \leq 3}\left\{\alpha_{k}, 2 \alpha_{4}\right\}$ such that $T$ is generalized $\alpha$ - $\beta$-proximal quasi-contractive.

Moreover, suppose that one of the following conditions holds:

- $\varphi$ is continuous;

- $\beta>\max \left\{\alpha_{2}, \alpha_{4}\right\}$.

Then $T$ has a best proximity point $x_{*} \in A$ such that $d\left(x_{*}, T x_{*}\right)=d(A, B)$. 
Theorem 3.3 In addition to the hypotheses of Theorem 3.2, suppose that $T$ is $(\alpha, d)$ regular and $\beta \geq \max \left\{\alpha_{0}, 2 \alpha_{1}, \alpha_{3}, \alpha_{4}\right\}$. Then $T$ has a unique best proximity point.

To prove the above theorems, we require the following lemma.

Lemma 3.4 Let $T: A \longrightarrow B$ be a non-self-mapping and $\alpha: A \times A \longrightarrow[0,+, \infty)$, satisfying the following conditions:

(1) $T\left(A_{0}\right) \subset B_{0}$;

(2) $T$ is $\alpha$-proximal admissible;

(3) there exist elements $x_{0}, x_{1} \in A$ such that $d\left(x_{1}, T x_{0}\right)=d(A, B)$ and $\alpha\left(x_{0}, x_{1}\right) \geq 1$;

then there exists a sequence $\left\{x_{n}\right\} \subset A_{0}$ such that $d\left(x_{n+1}, T x_{n}\right)=d(A, B)$ and $\alpha\left(x_{n}, x_{n+1}\right) \geq 1$. Such a sequence $\left\{x_{n}\right\}$ is a Cauchy sequence.

Proof Thanks to condition (3), there exist $x_{0}, x_{1} \in A$ such that $d\left(x_{1}, T x_{0}\right)=d(A, B)$ and $\alpha\left(x_{0}, x_{1}\right) \geq 1$. As $T\left(A_{0}\right) \subset B_{0}$, there exists $x_{2} \in A_{0}$ such that $d\left(x_{2}, T x_{1}\right)=d(A, B)$. As $T$ is $\alpha$ proximal admissible and using $\alpha\left(x_{0}, x_{1}\right) \geq 1, d\left(x_{1}, T x_{0}\right)=d\left(x_{2}, T x_{1}\right)=d(A, B)$, this implies that $\alpha\left(x_{1}, x_{2}\right) \geq 1$.

In a similar fashion, by induction, we can build a sequence $\left\{x_{n}\right\} \subset A_{0}$ such that

$$
d\left(x_{n+1}, T x_{n}\right)=d(A, B) \quad \text { and } \quad \alpha\left(x_{n}, x_{n+1}\right) \geq 1 \quad \text { for all } n \in \mathbb{N} \cup\{0\} .
$$

Our next step is to prove that the sequence $\left\{x_{n}\right\}$ is a Cauchy sequence.

Using the P-property, we deduce from (3.2) that

$$
d\left(x_{n}, x_{n+1}\right)=d\left(T x_{n-1}, T x_{n}\right), \quad \forall n \in \mathbb{N} .
$$

Since $T$ is generalized $\alpha$ - $\beta$-proximal quasi-contractive, there exists a function $\varphi \in \Phi_{\beta}$ such that

$$
\alpha\left(x_{n-1}, x_{n}\right) d\left(T x_{n-1}, T x_{n}\right) \leq \varphi\left(M_{T}\left(x_{n-1}, x_{n}\right)\right), \quad \forall n \in \mathbb{N} .
$$

On the other hand, using (3.2), (3.3) and the triangular inequality, we get

$$
\begin{aligned}
M_{T}\left(x_{n-1}, x_{n}\right)= & \max \left\{\alpha_{0} d\left(x_{n-1}, x_{n}\right), \alpha_{1}\left(d\left(x_{n-1}, T x_{n-1}\right)-d(A, B)\right),\right. \\
& \alpha_{2}\left(d\left(x_{n}, T x_{n}\right)-d(A, B)\right), \alpha_{3}\left(d\left(x_{n}, T x_{n-1}\right)-d(A, B)\right), \\
& \left.\alpha_{4}\left(d\left(x_{n-1}, T x_{n}\right)-d(A, B)\right)\right\} \\
= & \max \left\{\alpha_{0} d\left(x_{n-1}, x_{n}\right), \alpha_{1}\left(d\left(x_{n-1}, T x_{n-1}\right)-d(A, B)\right),\right. \\
& \left.\alpha_{2}\left(d\left(x_{n}, T x_{n}\right)-d(A, B)\right), \alpha_{4}\left(d\left(x_{n-1}, T x_{n}\right)-d(A, B)\right)\right\} \\
\leq & \max \left\{\alpha_{0} d\left(x_{n-1}, x_{n}\right), \alpha_{1} d\left(x_{n-1}, x_{n}\right), \alpha_{2} d\left(x_{n}, x_{n+1}\right),\right. \\
& \left.\alpha_{4} d\left(x_{n-1}, x_{n}\right)+\alpha_{4} d\left(x_{n}, x_{n+1}\right)\right\} \\
\leq & \beta \max \left\{d\left(x_{n-1}, x_{n}\right), d\left(x_{n}, x_{n+1}\right)\right\} .
\end{aligned}
$$

Hence,

$$
M_{T}\left(x_{n-1}, x_{n}\right) \leq \beta \max \left\{d\left(x_{n-1}, x_{n}\right), d\left(x_{n}, x_{n+1}\right)\right\},
$$


where $\beta \geq \max _{0 \leq k \leq 3}\left\{\alpha_{k}, 2 \alpha_{4}\right\}$. Using inequalities (3.3), (3.4) and (3.5) and taking into consideration the fact that $\varphi$ is nondecreasing, we get that

$$
d\left(x_{n+1}, x_{n}\right) \leq \varphi\left(\beta \max \left\{d\left(x_{n-1}, x_{n}\right), d\left(x_{n}, x_{n+1}\right)\right\}\right)=\varphi_{\beta}\left(\max \left\{d\left(x_{n-1}, x_{n}\right), d\left(x_{n}, x_{n+1}\right)\right\}\right) .
$$

Assume that, for some $n$, we have $d\left(x_{n-1}, x_{n}\right) \leq d\left(x_{n}, x_{n+1}\right)$. It follows that $d\left(x_{n+1}, x_{n}\right) \leq$ $\varphi_{\beta}\left(d\left(x_{n+1}, x_{n}\right)\right)<d\left(x_{n+1}, x_{n}\right)$, which is a contradiction.

Therefore, for all $n \geq 0$, we have necessary the inequality $d\left(x_{n-1}, x_{n}\right)>d\left(x_{n}, x_{n+1}\right)$. It follows that

$$
d\left(x_{n+1}, x_{n}\right) \leq \varphi_{\beta}\left(d\left(x_{n-1}, x_{n}\right)\right), \quad \forall n \in \mathbb{N} .
$$

By induction, we obtain that

$$
d\left(x_{n+1}, x_{n}\right) \leq \varphi_{\beta}^{n}\left(d\left(x_{1}, x_{0}\right)\right), \quad \forall n \in \mathbb{N} \cup\{0\} .
$$

Using the triangular inequality and the above inequality (3.7), we get

$$
\begin{aligned}
d\left(x_{n}, x_{m}\right) & \leq \sum_{k=n}^{m-1} d\left(x_{k}, x_{k+1}\right) \\
& \leq \sum_{k=n}^{m-1} \varphi_{\beta}^{k}\left(d\left(x_{1}, x_{0}\right)\right) \longrightarrow 0 \quad \text { as } n, m \longrightarrow+\infty
\end{aligned}
$$

since the series $\sum_{n=1}^{+\infty} \varphi_{\beta}^{n}\left(d\left(x_{1}, x_{0}\right)\right)$ converges. Thus, the sequence is a Cauchy sequence in the metric space $(X, d)$.

Proof of Theorem 3.2 The fact that $(X, d)$ is complete and $A$ is closed assures that the sequence $\left\{x_{n}\right\}$ converges to some element $x_{*} \in A$.

Using hypothesis (4) of the theorem, there exists a subsequence $\left\{x_{n(k)}\right\}$ of $\left\{x_{n}\right\}$ such that $\alpha\left(x_{n(k)}, x_{*}\right) \geq 1$ for all $k$. Since $T$ is generalized $\alpha$ - $\beta$-proximal quasi-contractive, then we have

$$
\begin{aligned}
d\left(T\left(x_{n(k)}, T x_{*}\right)\right. & \leq \alpha\left(x_{n(k)}, x_{*}\right) d\left(T\left(x_{n(k)}, T x_{*}\right)\right. \\
& \leq \varphi\left(M_{T}\left(x_{n(k)}, x_{*}\right)\right), \quad \forall k,
\end{aligned}
$$

where

$$
\begin{aligned}
M_{T}\left(x_{n(k)}, x_{*}\right)= & \max \left\{\alpha_{0} d\left(x_{n(k)}, x_{*}\right), \alpha_{1}\left(d\left(x_{n(k)}, T x_{n(k)}\right)-d(A, B)\right),\right. \\
& \alpha_{2}\left(d\left(x_{*}, T x_{*}\right)-d(A, B)\right), \alpha_{3}\left(d\left(x_{*}, T x_{n(k)}\right)-d(A, B)\right), \\
& \left.\alpha_{4}\left(d\left(x_{n(k)}, T x_{*}\right)-d(A, B)\right)\right\} .
\end{aligned}
$$

By the triangular inequality and (3.2), we have

$$
\begin{aligned}
d\left(x_{*}, T x_{*}\right) & \leq d\left(x_{*}, x_{n(k)+1}\right)+d\left(x_{n(k)+1}, T x_{n(k)}\right)+d\left(T x_{n(k)}, T x_{*}\right) \\
& =d\left(x_{*}, x_{n(k)+1}\right)+d(A, B)+d\left(T x_{n(k)}, T x_{*}\right) .
\end{aligned}
$$


We obtain that

$$
d\left(T x_{n(k)}, T x_{*}\right) \geq d\left(x_{*}, T x_{*}\right)-d\left(x_{*}, x_{n(k)+1}\right)-d(A, B), \quad \forall k .
$$

Using (3.8) and (3.11), we get

$$
\begin{gathered}
d\left(x_{*}, T x_{*}\right)-d\left(x_{*}, x_{n(k)+1}\right)-d(A, B) \\
\leq \varphi\left(M_{T}\left(x_{n(k)}, x_{*}\right)\right), \quad \forall k .
\end{gathered}
$$

In addition, by the triangular inequality and (3.2) on (3.9), we get

$$
\begin{aligned}
M_{T}\left(x_{n(k)}, x_{*}\right) \leq & \max \left\{\alpha_{0} d\left(x_{n(k)}, x_{*}\right), \alpha_{1} d\left(x_{n(k)}, x_{n(k)+1}\right),\right. \\
& \alpha_{2}\left(d\left(x_{*}, T x_{*}\right)-d(A, B)\right), \alpha_{3} d\left(x_{*}, x_{n(k)+1}\right), \\
& \left.\alpha_{4}\left(d\left(x_{n(k)}, T x_{*}\right)-d(A, B)\right)\right\} .
\end{aligned}
$$

As $\varphi$ is nondecreasing, combining inequalities (3.12) and (3.13), we obtain

$$
\begin{aligned}
& d\left(x_{*}, T x_{*}\right)-d\left(x_{*}, x_{n(k)+1}\right)-d(A, B) \\
& \leq \varphi\left(\operatorname { m a x } \left\{\alpha_{0} d\left(x_{n(k)}, x_{*}\right), \alpha_{1} d\left(x_{n(k)}, x_{n(k)+1}\right),\right.\right. \\
& \alpha_{2}\left(d\left(x_{*}, T x_{*}\right)-d(A, B)\right), \alpha_{3} d\left(x_{*}, x_{n(k)+1}\right), \\
&\left.\left.\alpha_{4}\left(d\left(x_{n(k)}, T x_{*}\right)-d(A, B)\right)\right\}\right) .
\end{aligned}
$$

Assume $\rho=d\left(x_{*}, T x_{*}\right)-d(A, B)>0$.

We consider two separate cases as follows.

If $\varphi$ is continuous, as $k \longrightarrow+\infty$, we get

$$
\begin{aligned}
\rho & \leq \varphi\left(\max \left\{\alpha_{2}, \alpha_{4}\right\} \rho\right) \\
& \leq \varphi(\beta \rho)<\rho,
\end{aligned}
$$

which is a contradiction.

If $\beta>\max \left\{\alpha_{2}, \alpha_{4}\right\}$, we claim also that $\rho=0$. Suppose by contradiction that $\rho>0$.

Letting $k \longrightarrow+\infty$ in (3.9), we get $M_{T}\left(x_{n(k)}, x_{*}\right) \longrightarrow \max \left\{\alpha_{2}, \alpha_{4}\right\} \rho$. Then there exists $\varepsilon>0$ and $N>0$ such that for all $n>N$, we have

$$
M_{T}\left(x_{n(k)}, x_{*}\right)<\left(\max \left\{\alpha_{2}, \alpha_{4}\right\}+\varepsilon\right) \rho \quad \text { and } \quad \beta>\max \left\{\alpha_{2}, \alpha_{4}\right\}+\varepsilon
$$

Therefore,

$$
\begin{aligned}
& d\left(x_{*}, T x_{*}\right)-d\left(x_{*}, x_{n(k)+1}\right)-d(A, B) \\
& \quad \leq \varphi\left(M_{T}\left(x_{n(k)}, x_{*}\right)\right) \\
& \quad \leq \varphi\left(\left(\max \left\{\alpha_{2}, \alpha_{4}\right\}+\varepsilon\right) \rho\right)=\varphi_{\beta}\left(\frac{\max \left\{\alpha_{2}, \alpha_{4}\right\}+\varepsilon}{\beta} \rho\right) \\
& \quad<\frac{\max \left\{\alpha_{2}, \alpha_{4}\right\}+\varepsilon}{\beta} \rho<\rho .
\end{aligned}
$$


Consequently, by letting $k \rightarrow \infty$, we get

$$
\rho<\frac{\max \left\{\alpha_{2}, \alpha_{4}\right\}+\varepsilon}{\beta} \rho<\rho,
$$

which is a contradiction as well. Hence, our claim holds. Thus, we prove that $x_{*}$ is a best proximity point of $T$, that is,

$$
d\left(x_{*}, T x_{*}\right)=d(A, B)
$$

Proof of Theorem 3.3 For the uniqueness, suppose that $x_{*}$ and $y_{*}$ are two distinct best proximity points of $T$. Let $s=d\left(x_{*}, y_{*}\right)>0$. Using the P-property, we obtain $d\left(T x_{*}, T y_{*}\right)=$ $d\left(x_{*}, y_{*}\right)=s$. We consider two cases.

If $\alpha\left(x_{*}, y_{*}\right) \geq 1$. Since $T$ is a generalized $\alpha$ - $\beta$-proximal quasi-contraction, this gives

$$
\begin{aligned}
d\left(T x_{*}, T y_{*}\right) & =s \\
& \leq \alpha\left(x_{*}, y_{*}\right) \varphi\left(M_{T}\left(x_{*}, y_{*}\right)\right),
\end{aligned}
$$

where

$$
\begin{aligned}
M_{T}\left(x_{*}, y_{*}\right)= & \max \left\{\alpha_{0} d\left(x_{*}, y_{*}\right), \alpha_{1}\left(d\left(x_{*}, T x_{*}\right)-d(A, B)\right),\right. \\
& \alpha_{2}\left(d\left(y_{*}, T y_{*}\right)-d(A, B)\right), \alpha_{3}\left(d\left(y_{*}, T x_{*}\right)-d(A, B)\right), \\
& \left.\alpha_{4}\left(d\left(x_{*}, T y_{*}\right)-d(A, B)\right)\right\} \\
= & \max \left\{\alpha_{0} d\left(x_{*}, y_{*}\right), \alpha_{3}\left(d\left(y_{*}, T x_{*}\right)-d(A, B)\right),\right. \\
& \left.\alpha_{4}\left(d\left(x_{*}, T y_{*}\right)-d(A, B)\right)\right\} .
\end{aligned}
$$

Using the triangular inequality in (3.17), we obtain

$$
M_{T}\left(x_{*}, y_{*}\right) \leq \max \left\{\alpha_{0}, \alpha_{3}, \alpha_{4}\right\}
$$

Combining (3.16) and (3.18) and using the nondecreasing property of the function $\varphi$, we conclude that

$$
s \leq \varphi_{\beta}(s)<s,
$$

which is a contradiction. So, $s=0$ and therefore $x_{*}=y_{*}$.

If $\alpha\left(x_{*}, y_{*}\right)<1$. Since $T$ is $(\alpha, d)$ regular, there exists $u_{0} \in A_{0}$ such that $\alpha\left(x_{*}, u_{0}\right) \geq 1$ and $\alpha\left(y_{*}, u_{0}\right) \geq 1$. Since $T\left(A_{0}\right) \subset B_{0}$, there exists $u_{1} \in A_{0}$ such that $d\left(u_{1}, T u_{0}\right)=d(A, B)$.

We have $d\left(x_{*}, T x_{*}\right)=d\left(u_{1}, T u_{0}\right)=d(A, B)$ and $\alpha\left(x_{*}, u_{0}\right) \geq 1$.

Using the fact that $T$ is $\alpha$-proximal admissible, we get $\alpha\left(x_{*}, u_{1}\right) \geq 1$.

One can proceed further in a similar fashion to find $\left\{u_{n}\right\} \in A_{0}$ such that

$$
d\left(u_{n+1}, T u_{n}\right)=d(A, B), \quad \alpha\left(x_{*}, u_{n}\right) \geq 1, \quad \text { for all } n \in \mathbb{N} \cup\{0\} .
$$


Using the P-property and (3.19), we have

$$
d\left(u_{n+1}, x_{*}\right)=d\left(T u_{n}, T x_{*}\right) \quad \text { for all } n \in \mathbb{N} \cup\{0\} .
$$

As $T$ is generalized $\alpha$ - $\beta$-proximal quasi-contractive, then we get

$$
\alpha\left(u_{n+1}, x_{*}\right) d\left(T u_{n+1}, T x_{*}\right) \leq \varphi\left(M_{T}\left(u_{n}, x_{*}\right)\right) \quad \text { for all } n \in \mathbb{N} \cup\{0\} .
$$

Using (3.19) and (3.21), we get

$$
\alpha\left(u_{n+1}, x_{*}\right) d\left(u_{n+1}, x_{*}\right) \leq \varphi\left(M_{T}\left(u_{n}, x_{*}\right)\right) \quad \text { for all } n \in \mathbb{N} \cup\{0\} .
$$

Therefore, from (3.19), we conclude that

$$
d\left(u_{n+1}, x_{*}\right) \leq \varphi\left(M_{T}\left(u_{n}, x_{*}\right)\right) \quad \text { for all } n \in \mathbb{N} \cup\{0\} .
$$

On the other hand, using (3.15), for all $n \in \mathbb{N} \cup\{0\}$, we obtain

$$
\begin{aligned}
M_{T}\left(u_{n}, x_{*}\right)= & \max \left\{\alpha_{0} d\left(u_{n}, x_{*}\right), \alpha_{1}\left(d\left(u_{n}, T u_{n}\right)-d(A, B)\right), \alpha_{2}\left(d\left(x_{*}, T x_{*}\right)-d(A, B)\right),\right. \\
& \left.\alpha_{3}\left(d\left(x_{*}, T u_{n}\right)-d(A, B)\right), \alpha_{4}\left(d\left(u_{n}, T x_{*}\right)-d(A, B)\right)\right\} \\
= & \max \left\{\alpha_{0} d\left(u_{n}, x_{*}\right), \alpha_{1}\left(d\left(u_{n}, T u_{n}\right)-d(A, B)\right), \alpha_{3}\left(d\left(x_{*}, T u_{n}\right)-d(A, B)\right),\right. \\
& \left.\alpha_{4}\left(d\left(u_{n}, T x_{*}\right)-d(A, B)\right)\right\} .
\end{aligned}
$$

Using the triangular inequality and (3.20) in the above expression (3.24), and taking into consideration (3.15), we get

$$
\begin{aligned}
M_{T}\left(u_{n}, x_{*}\right) \leq & \max \left\{\alpha_{0} d\left(u_{n}, x_{*}\right), \alpha_{1} d\left(u_{n}, x_{*}\right)+\alpha_{1} d\left(x_{*}, T x_{*}\right)+\alpha_{1} d\left(T x_{*}, T u_{n}\right)-\alpha_{1} d(A, B),\right. \\
& \alpha_{3} d\left(x_{*}, u_{n+1}\right)+\alpha_{3} d\left(u_{n+1}, T u_{n}\right)-\alpha_{3} d(A, B), \\
& \left.\alpha_{4} d\left(u_{n}, x_{*}\right)+\alpha_{4} d\left(x_{*}, T x_{*}\right)-\alpha_{4} d(A, B)\right\} \\
= & \max \left\{\alpha_{0} d\left(u_{n}, x_{*}\right), \alpha_{1} d\left(u_{n}, x_{*}\right)+\alpha_{1} d\left(u_{n+1}, x_{*}\right), \alpha_{3} d\left(x_{*}, u_{n+1}\right), \alpha_{4} d\left(u_{n}, x_{*}\right)\right\} \\
\leq & \beta \max \left\{d\left(u_{n}, x_{*}\right), d\left(u_{n+1}, x_{*}\right)\right\} .
\end{aligned}
$$

Since $\alpha\left(u_{n+1}, x_{*}\right) \geq 1$, combining (3.25) and (3.23), we get that

$$
d\left(u_{n+1}, x_{*}\right) \leq \varphi_{\beta}\left(\max \left\{d\left(u_{n}, x_{*}\right), d\left(u_{n+1}, x_{*}\right)\right\}\right), \quad \forall n \in \mathbb{N} \cup\{0\},
$$

where $\beta \geq \max \left\{\alpha_{0}, 2 \alpha_{1}, \alpha_{3}, \alpha_{4}\right\}$. Assume that, for some $n$, we have $d\left(u_{n}, x_{*}\right) \leq d\left(u_{n+1}, x_{*}\right)$. We have from (3.26)

$$
d\left(u_{n+1}, x_{*}\right) \leq \varphi_{\beta}\left(d\left(u_{n+1}, x_{*}\right)\right)<d\left(u_{n+1}, x_{*}\right)
$$

which is a contradiction. 
Therefore, for all $n \geq 0$, we have $d\left(u_{n+1}, x_{*}\right)<d\left(u_{n}, x_{*}\right)$. Using (3.26), we have

$$
d\left(u_{n+1}, x_{*}\right) \leq \varphi_{\beta}\left(d\left(u_{n}, x_{*}\right)\right) \text { for all } n \text {. }
$$

By induction, we obtain

$$
d\left(u_{n}, x_{*}\right) \leq \varphi_{\beta}^{n}\left(d\left(u_{0}, x_{*}\right)\right) \quad \text { for all } n \in \mathbb{N} \cup\{0\} .
$$

Hence, by letting $n \longrightarrow+\infty$ in the above inequality, we obtain that $\left\{u_{n}\right\}$ converges to $x_{*}$.

Analogously, we can prove that $\left\{u_{n}\right\}$ converges to $y_{*}$. Using the uniqueness of limit, we conclude that $x_{*}=y_{*}$.

Example Consider the complete Euclidian space $X=\mathbb{R}^{2}$ with the metric $d\left(\left(x_{1}, x_{2}\right),\left(y_{1}, y_{2}\right)\right)=\left|x_{1}-x_{2}\right|+\left|y_{1}-y_{2}\right|$. Let $A=\{(\gamma, 0): \gamma \in[0,1]\}$ and $B=\{(\delta, 1): \delta \in[0,1]\}$. Also, let $T: A \longrightarrow B$ be defined by $T(\gamma, 0)=\left(\frac{\gamma}{4}, 1\right)$. Then it is easy to see that $d(A, B)=$ 1 and $A_{0}=A, B_{0}=B$. Now, we shall show that $T$ is an $\alpha-\beta$-proximal quasi-contractive mapping with $\varphi(t)=\frac{3}{4} t, \alpha \equiv 1$, and $\beta_{1}=\frac{3}{4}$ and $\alpha_{i}=\frac{1}{3^{i+1}}$ for $i=0,1,2,3,4$.

Let $x, y \in A$, where $x=\left(\gamma_{1}, 0\right)$ and $y=\left(\gamma_{2}, 0\right)$.

$$
\begin{aligned}
d(T x, T y)= & d\left(\left(\frac{\gamma_{1}}{4}, 0\right),\left(\frac{\gamma_{2}}{4}, 0\right)\right) \\
= & \frac{1}{4}\left|\gamma_{1}-\gamma_{2}\right| \\
= & \frac{1}{4} d(x, y) \\
= & \frac{3}{4}\left(\frac{1}{3} d(x, y)\right) \\
\leq & \frac{3}{4} \max \left\{\frac{1}{3} d(x, y), \frac{1}{9}(d(x, T x)-d(A, B)), \frac{1}{27}(d(y, T y)-d(A, B)),\right. \\
& \left.\frac{1}{81}(d(y, T x)-d(A, B)), \frac{1}{243}(d(x, T y)-d(A, B))\right\} .
\end{aligned}
$$

So, $T$ is an $\alpha-\beta$-proximal quasi-contractive mapping with $\alpha(x, y)=1$ for all $x, y \in A$ and $\varphi(t)=\frac{3}{4} t, \beta=\frac{3}{4}$ and $\alpha_{i}=\frac{1}{3^{i+1}}$ for $i=0,1,2,3,4$. Since $\beta=\frac{3}{4} \geq \max _{0 \leq k \leq 3}\left\{\alpha_{k}, 2 \alpha_{4}\right\}$.

It is easy to see that the pair $(A, B)$ satisfies the P-property.

Since $\alpha(x, y)=1$ for all $x, y \in A$, then the mapping $T$ is $\alpha$-admissible. Also the fact that $\beta=$ $\frac{3}{4} \geq \max \left\{\frac{1}{3}, \frac{2}{9}, \frac{1}{81}, \frac{1}{243}\right\}=\max \left\{\alpha_{0}, 2 \alpha_{1}, \alpha_{3}, \alpha_{4}\right\}=\frac{1}{3}$ and $T$ is $(\alpha, d)$ regular since $\alpha \equiv 1$ assures the uniqueness of the proximity point of $T$. Therefore, all the conditions of Theorems 3.2 and 3.3 are satisfied, and so $T$ has a unique proximity point which is $x_{*}=(0,0) \in A$.

$$
d((0,0), T(0,0))=d((0,0),(0,1))=1=d(A, B) .
$$

\section{Consequences}

Several consequences of the main theorems are suggested in this section.

Corollary 4.1 ([9]) Let $A$ and $B$ be nonempty closed subsets of a complete metric space $(X, d)$ such that $A_{0}$ is nonempty. Let $\alpha: A \times A \longrightarrow[0,+\infty)$ and $\psi \in \Psi$. Suppose that $T:$ $A \longrightarrow B$ is a non-self-mapping satisfying the following conditions: 
(1) $T\left(A_{0}\right) \subset B_{0}$, and $(A, B)$ satisfies the P-property;

(2) $T$ is $\alpha$-proximal admissible;

(3) there exist elements $x_{0}$ and $x_{1}$ such that

$$
d\left(x_{1}, T x_{0}\right)=d(A, B), \quad \alpha\left(x_{0}, x_{1}\right) \geq 1 ;
$$

(4) $T$ is a generalized $\alpha-\psi$ proximal contraction;

(5) if $\left\{x_{n}\right\}$ is a sequence in $A$ such that $\alpha\left(x_{n}, x_{n+1}\right) \geq 1$ and $\lim _{n \rightarrow+\infty} x_{n}=x_{*} \in A$, then

there exists a subsequence $\left\{x_{n(k)}\right\}$ of $\left\{x_{n}\right\}$ such that $\alpha\left(x_{n(k)}, x_{*}\right) \geq 1$ for all $k$.

Then there exists an element $x_{*} \in A_{0}$ such that $d\left(x_{*}, T x_{*}\right)=d(A, B)$.

Proof First, we notice that using $M(x, y)$ appearing in (2.1), we have the following inequality:

$$
\begin{aligned}
M(x, y) \leq & M_{T}(x, y) \\
= & \max \{d(x, y), d(x, T x)-d(A, B), \\
& d(y, T y)-d(A, B), d(y, T x)-d(A, B), \\
& d(x, T y)-d(A, B)\} .
\end{aligned}
$$

The existing best proximity point result follows immediately from Theorem 3.2 by taking $\psi=\varphi \in \Phi_{2}$ and $\beta \geq 2>\max \{1,1\}=1$.

Corollary 4.2 ([9]) In addition to the hypotheses of Corollary 4.1, suppose that $T$ is $(\alpha, d)$ regular. Then $T$ has a unique best proximity point.

Proof Also it is an immediate consequence of Theorem 3.3 since the assertion $\beta \geq$ $\max \left\{\alpha_{0}, 2 \alpha_{1}, \alpha_{3}, \alpha_{4}\right\}=2$ is satisfied, and therefore $\psi=\varphi \in \Phi_{2}$.

Corollary 4.3 Let $A$ and $B$ be nonempty closed subsets of a complete metric space $(X, d)$ such that $A_{0}$ is nonempty. Suppose that $T: A \longrightarrow B$ is a non-self-mapping satisfying the following conditions:

(1) $T\left(A_{0}\right) \subset B_{0}$, and $(A, B)$ satisfies the P-property;

(2) there exists $k \in(0,1)$ such that $d(T x, T y) \leq k d(x, y)$ for all $x, y \in A$.

Then there exists a unique element $x_{*} \in A_{0}$ such that $d\left(x_{*}, T x_{*}\right)=d(A, B)$.

Proof This follows immediately from Theorem 3.2 by taking $\alpha(x, y)=1$ for all $x, y \in A$ and $\varphi(t)=k t$ which is continuous, where $k \in(0,1)$. Since $\alpha(x, y)=1$ for all $x, y \in A$, then condition (4) of our main Theorem 3.2 occurs. So, there exists a best proximity point for $T$.

The fact that $\alpha(x, y)=1$ for all $x, y \in A$ guarantees that $T$ is $(\alpha, d)$ regular, which implies, by Theorem 3.3, that such a best proximity point for $T$ is unique.

\section{Applications}

\subsection{Best proximity points for metric spaces endowed with symmetric binary relations}

In order to apply our results on best proximity points on a metric space endowed with symmetric binary relation, we need some preliminaries.

Let $(X, d)$ be a metric space and $\mathcal{R}$ be a symmetric binary relation over $X$. 
Definition 5.1 ([9]) A non-self-mapping $T: A \longrightarrow B$ is a proximal comparative mapping if $x \mathcal{R} y$ and $d\left(u_{1}, T x\right)=d\left(u_{2}, T y\right)=d(A, B)$ for all $x, y, u_{1}, u_{2} \in A$, then $u_{1} \mathcal{R} u_{2}$.

Definition 5.2 ([12]) A subset $A$ of $X$ is called $\mathcal{R}$-directed if, for every $x, y \in A$, there exists $z \in X$ such that $x \mathcal{R} z$ and $y \mathcal{R} z$.

Definition 5.3 ([13]) We say that $(X, d, \mathcal{R})$ is regular if, for a sequence $\left\{x_{n}\right\}$ in $X$, if we have $x_{n} \mathcal{R} x_{n+1}$ for all $n \in \mathbb{N}_{0}$ and $\lim _{n \rightarrow \infty} d\left(x_{n}, x\right)=0$ for some $x \in X$, then there exists a subsequence $\left\{x_{n(k)}\right\}$ of $\left\{x_{n}\right\}$ such that $x_{n(k)} \mathcal{R} x$ for all $k \in \mathbb{N}_{0}$.

Definition 5.4 ([11]) Let $X$ be a nonempty set. A non-self-mapping $T: A \rightarrow B$ is called $\beta$-quasi-contractive if there exist $\beta>0$ and $\varphi \in \Phi_{\beta}$ such that

$$
x, y \in A: x \mathcal{R} y \quad \Longrightarrow \quad d(T x, T y) \leq \varphi\left(M_{T}(x, y)\right)
$$

where

$$
M_{T}(x, y)=\max \left\{\alpha_{0} d(x, y), \alpha_{1} d(x, T x), \alpha_{2} d(y, T y), \alpha_{3} d(x, T y), \alpha_{4} d(y, T x)\right\}
$$

with $\alpha_{k} \geq 0$ for $k=0, \ldots, 4$.

We have the following best proximity point result.

Corollary 5.5 Let $(A, B)$ be a pair of nonempty closed subsets of a complete metric space $(X, d)$ such that $A_{0}$ is nonempty. Let $\mathcal{R}$ be a symmetric binary relation over $X$. Consider a non-self-mapping $T: A \longrightarrow B$ satisfying the following assertions:

(1) $T\left(A_{0}\right) \subset B_{0}$ and the pair $(A, B)$ satisfies the P-property;

(2) $T$ is a proximal comparative mapping;

(3) there exist elements $x_{0}, x_{1} \in A_{0}$ such that $d\left(x_{1}, T x_{0}\right)=d(A, B)$ and $x_{0} \mathcal{R} x_{1}$;

(4) if $(A, d, \mathcal{R})$ is regular;

(5) there exists $\beta \geq \max _{0 \leq k \leq 3}\left\{\alpha_{k}, 2 \alpha_{4}\right\}$ such that $T: A \rightarrow B$ is $\beta$-quasi-contractive.

Moreover, assume that one of the following conditions holds:

- $\varphi$ is continuous;

- $\beta>\max \left\{\alpha_{2}, \alpha_{4}\right\}$.

Then $T$ has a best proximity point $x_{*} \in A$ such that $d\left(x_{*}, T x_{*}\right)=d(A, B)$.

Proof Let us define the mapping $\alpha: A \times A \longrightarrow[0,+\infty)$ by:

$$
\alpha(x, y)= \begin{cases}1 & \text { if } x \neq y \\ 0 & \text { otherwise }\end{cases}
$$

In order to apply our Theorem 3.2, we have to prove that $T$ is $\alpha$-admissible.

Assume that $\alpha(x, y) \geq 1$, and $d\left(u_{1}, T x\right)=d\left(u_{2}, T x\right)=d(A, B)$, for some $x, y, u_{1}, u_{2} \in A$. By the definition of $\alpha$, we get $x \mathcal{R} y$, and $d\left(u_{1}, T x\right)=d\left(u_{2}, T x\right)=d(A, B)$. Condition (2) of the corollary implies $u_{1} \mathcal{R} u_{2}$, which gives us $\alpha\left(u_{1}, u_{2}\right) \geq 1$.

Condition (3) means that $d\left(x_{1}, T x_{0}\right)=d(A, B)$ and $\alpha\left(x_{0}, x_{1}\right) \geq 1$. 
The condition $T: A \rightarrow B$ is $\beta$-quasi-contractive means that $T$ is generalized $\alpha-\beta$ proximal quasi-contractive. Also the condition $(A, d, \mathcal{R})$ is regular implies if $\left\{x_{n}\right\}$ is a sequence in $A$ such that $\alpha\left(x_{n}, x_{n+1}\right) \geq 1$ and $\lim _{n \rightarrow+\infty} x_{n}=x_{*} \in A$, then there exists a subsequence $\left\{x_{n(k)}\right\}$ of $\left\{x_{n}\right\}$ such that $\alpha\left(x_{n(k)}, x_{*}\right) \geq 1$ for all $k$.

Now all the hypotheses of Theorem 3.2 are satisfied, which implies the existence of a proximity point for the non-self-mapping $T$.

Corollary 5.6 In addition to the hypotheses of Corollary 5.5, suppose that $A$ is $\mathcal{R}$-directed and $\beta \geq \max \left\{\alpha_{0}, 2 \alpha_{1}, \alpha_{3}, \alpha_{4}\right\}$. Then $T$ has a unique best proximity point.

Proof The fact that $A$ is $\mathcal{R}$-directed implies that the non-self-mapping $T: A \longrightarrow B$ is $(\alpha, d)$ regular. So, by Theorem 3.3, we deduce the uniqueness of a best proximity point for $T$.

\subsection{Application to fixed point results}

Let us recall the following definition.

Definition 5.7 Let $A$ be a nonempty set of a metric space $(X, d)$. A self-mapping $T: A \rightarrow A$ is called a generalized $\alpha$ - $\beta$-quasi-contractive if there exist two functions $\alpha: A \times A \longrightarrow$ $[0,+\infty)$ and $\varphi \in \Phi_{\beta}$, where $\beta>0$, such that, for all $x, y \in A$, we have

$$
\alpha(x, y) d(T x, T y) \leq \varphi\left(M_{T}(x, y)\right)
$$

where

$$
M_{T}(x, y)=\max \left\{\alpha_{0} d(x, y), \alpha_{1} d(x, T x), \alpha_{2} d(y, T y), \alpha_{3} d(x, T y), \alpha_{4} d(y, T x)\right\},
$$

with $\alpha_{k} \geq 0$ for $k=0, \ldots, 4$.

By considering the particular case, $A=B$ in Theorems 3.2 and 3.3, the fixed point results were deduced as follows.

Corollary 5.8 Let $A$ be a nonempty closed subset of a complete metric space $(X, d)$. Let $T: A \rightarrow A$ be an $\alpha$ - $\beta$-quasi-contractive mapping, where $\beta \geq \max _{0 \leq k \leq 3}\left\{\alpha_{k}, 2 \alpha_{4}\right\}$, satisfying the following assertions:

(1) $T$ is $\alpha$-proximal admissible;

(2) there exist elements $x_{0}, x_{1} \in A$ such that $\alpha\left(x_{0}, x_{1}\right) \geq 1$;

(3) if $\left\{x_{n}\right\}$ is a sequence in $A$ such that $\alpha\left(x_{n}, x_{n+1}\right) \geq 1$ for all $n$ and $\lim _{n \rightarrow+\infty} x_{n}=x_{*} \in A$, then there exists a subsequence $\left\{x_{n(k)}\right\}$ of $\left\{x_{n}\right\}$ such that $\alpha\left(x_{n(k)}, x_{*}\right) \geq 1$ for all $k$.

Moreover, suppose that one of the following conditions holds:

- $\varphi$ is continuous;

- $\beta>\max \left\{\alpha_{2}, \alpha_{4}\right\}$.

Then $T$ has a fixed point.

Corollary 5.9 In addition to the hypotheses of Corollary 5.8 , suppose that $T$ is $(\alpha, d)$ regular and $\beta \geq \max \left\{\alpha_{0}, 2 \alpha_{1}, \alpha_{3}, \alpha_{4}\right\}$. Then $T$ has a unique fixed point. 


\section{Conclusion}

We recall that we have given in this paper some improvements to the best proximity point theorems previously made by JM, KE and SB in [9] for $\alpha$ - $\psi$-proximal contractive mappings. This improvement was obtained by introducing the proximal $\alpha$ - $\beta$-quasicontractive mappings on metric spaces involving $\beta$-comparison functions. As applications, we have established not only the existence but the uniqueness of best proximity point results for the case of non-self-mappings on metric spaces endowed with symmetric binary relations.

\section{Competing interests}

The authors declare that they have no competing interests.

\section{Authors' contributions}

Author read and approved the final manuscript.

\section{Publisher's Note}

Springer Nature remains neutral with regard to jurisdictional claims in published maps and institutional affiliations.

Received: 27 May 2017 Accepted: 4 September 2017 Published online: 01 November 2017

\section{References}

1. Al-Thagafi, MA, Shahzad, N: Convergence and existence results for best proximity points. Nonlinear Anal. 70, 3665-3671 (2009)

2. Al-Thagafi, MA, Shahzad, N: Best proximity sets and equilibrium pairs for a finite family of multimaps. Fixed Point Theory Appl. 10, Article ID 457069 (2008)

3. Sadiq Basha, S, Veeramani, P: Best approximations and best proximity pairs. Acta Sci. Math. 63, 289-300 (1997)

4. Sadiq Basha, S, Veeramani, P, Pai, DV: Best proximity pair theorems. Indian J. Pure Appl. Math. 32, 1237-1246 (2001)

5. Sadiq Basha, S, Veeramani, P: Best proximity pair theorems for multifunctions with open fibres. J. Approx. Theory 103, 119-129 (2000)

6. Karupunar, E: Best proximity points of Kannan type-cyclic weak phi-contractions in ordered metric spaces. An. Ştiinţ. Univ. 'Ovidius' Constanţa 20, 51-64 (2012)

7. Raj, VS: A best proximity point theorem for weakly contractive non-self-mappings. Nonlinear Anal. 74, 4804-4808 (2011)

8. Vetro, C: Best proximity points: convergence and existence theorems for P-cyclic-mappings. Nonlinear Anal. 73, 2283-2291 (2010)

9. Jleli, M, Karapunar, E, Samet, B: Best proximity points for generalized $\alpha$ - $\psi$-proximal contractive type mapping. J. Appl. Math. 2013, Article ID 534127 (2013)

10. Sadiq Bacha, S: Extensions of Banach's contraction principle. Numer. Funct. Anal. Optim. 31, 569-576 (2010)

11. Ayari, MI, Berzig, M, Kedim, I: Coincidence and common fixed point results for $\beta$-quasi contractive mappings on metric spaces endowed with binary relation. Math. Sci. 10(3), 105-114 (2016)

12. Berzig, M: Coincidence and common fixed point results on metric spaces endowed with an arbitrary binary relation and applications. J. Fixed Point Theory Appl. 12, 221-238 (2012)

13. Samet, B, Turinci, M: Fixed points theorems on a metric space endowed with an arbitrary binary relation and applications. Commun. Math. Anal. 13, 82-97 (2012)

\section{Submit your manuscript to a SpringerOpen ${ }^{\circ}$ journal and benefit from:}

- Convenient online submission

- Rigorous peer review

- Open access: articles freely available online

- High visibility within the field

- Retaining the copyright to your article 